\title{
National Trends in Lumbar Puncture from 2010 to 2018: A Shift Reversal from the Emergency Department to the Hospital Setting for Radiologists and Advanced Practice Providers
}

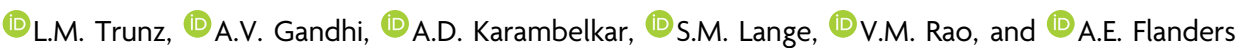

\section{ABSTRACT}

BACKGROUND AND PURPOSE: Prior research has shown substantial shifts in procedure shares between specialty groups providing lumbar punctures. Our aim was to analyze national trends in lumbar punctures among the Medicare population from 2010 to 2018.

\begin{abstract}
MATERIALS AND METHODS: Medicare Part B Physician/Supplier Procedure Summary Master Files from 2010 to 2018 were analyzed for all Current Procedural Terminology, Version 4 codes related to lumbar punctures (62270 and 62272). Lumbar puncture procedure volume and utilization rates were assessed and stratified by place of service and specialty background of the providers.

RESULTS: From 2010 to 2018, the overall number of lumbar puncture procedures essentially has not changed (92,579 versus 92,533$)$. Radiologists hold the largest and an increasing procedure share of diagnostic and overall lumbar punctures (overall share, $45.7 \%$ in $2010[n=42,296]$ versus $52.3 \%$ in 2018 [ $n=48,414])$. Advanced practice providers have increased their procedure share $(3.7 \%$ in 2010 [ $n=3388]$ versus $8.4 \%$ in 2018 [ $n=7785],+129.8 \%$ procedure volume). Emergency medicine physicians and neurologists have a decreasing procedure share $(21.8 \%$ versus $15.3 \%$ and $12.5 \%$ versus $8.8 \%$, respectively). The inpatient hospital setting remains the largest place of service for lumbar punctures, recording a $5.3 \%$ increase in procedure share. The emergency department lumbar puncture volume has declined, with a $7.4 \%$ decrease in the overall procedure share. Similarly, the hospital outpatient department procedure volume has increased $(+4 \%)$, while the private office volume has decreased $(-1.7 \%)$.
\end{abstract}

CONCLUSIONS: During the past decade, lumbar puncture procedures among the Medicare population have remained stable, with a shift in procedure volume from the emergency department and private offices to the hospital setting, which has mainly affected radiologists and advanced practice providers.

ABBREVIATIONS: APP = advanced practice provider; $E D=$ emergency department; $L P=$ lumbar puncture

D uring the past decades, lumbar punctures (LPs) have been progressively performed with image guidance, and associated with this trend were an increased responsibility and involvement of radiologists. ${ }^{1}$ For image guidance, fluoroscopy and CT perform equally well with low effective radiation dosages. ${ }^{2}$ Additionally, sonographic guidance can improve LP success rates, especially in a well-selected patient population. ${ }^{3}$

LPs are an essential part of the diagnostic work-up in various neurologic diseases and are divided into diagnostic and therapeutic. Primary indications for diagnostic LPs are suspected CNS infection and measurement of the CSF opening pressure;

Received July 6, 2020; accepted after revision August 11.

From the Department of Radiology, Thomas Jefferson University, Philadelphia, Pennsylvania.

Paper previously presented at: Annual Meeting of the American Society of Neuroradiology, May 30 to June 4, 2020; Virtual.

Please address correspondence to Lukas M. Trunz, MD, Thomas Jefferson University, Department of Radiology, Main Building, 132 S 10th St, Suite 780-A, Philadelphia, PA; e-mail: lukas.trunz@jefferson.edu

http://dx.doi.org/10.3174/ajnr.A6870 indications also include subarachnoid hemorrhage, CNS autoimmune disease, neoplastic meningeal disease, and dementia. Therapeutic LPs can be used to either lower the intracranial pressure, for example in the setting of cryptococcal meningitis or idiopathic intracranial hypertension; to administer medications intrathecally (eg, chemotherapy); or as a "shunt trial" in the context of normal pressure hydrocephalus. ${ }^{4}$

Compared with bedside/non-image-guided LPs, image guidance offers several advantages, and multiple factors may contribute to an increasing demand for service. Prior studies have demonstrated fewer traumatic LPs when using fluoroscopic guidance, ${ }^{5}$ which improves diagnostic work-up and patient comfort. The increasing prevalence of obesity in the general population ${ }^{6}$ resulted in further use of image guidance. ${ }^{7}$ Other factors favoring the use of image guidance are in the postoperative setting with hardware and/or osseous fusion or with extensive degenerative changes or scoliosis present. ${ }^{7}$ This shift led to radiologists becoming the dominant overall provider of LP procedures between 


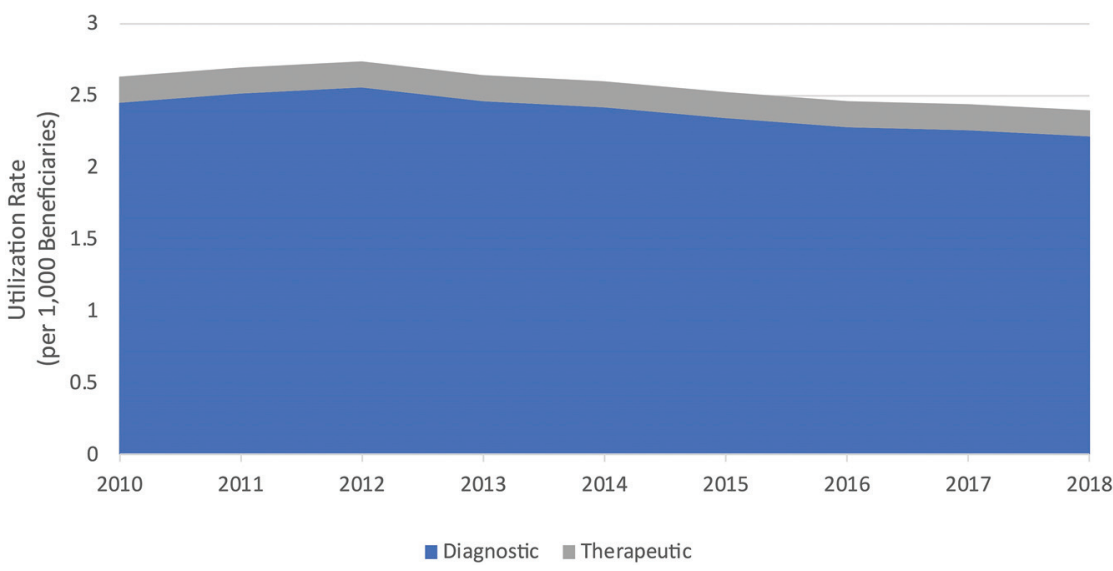

FIG 1. Lumbar puncture utilization rate (diagnostic and therapeutic LPs combined) per 1000 Medicare Fee-for-Service enrollees. After a peak in 2012, the procedure rate successively declined during the remaining decade, corresponding to a 9\% decrease of the overall procedure rate from 2010 to 2018.

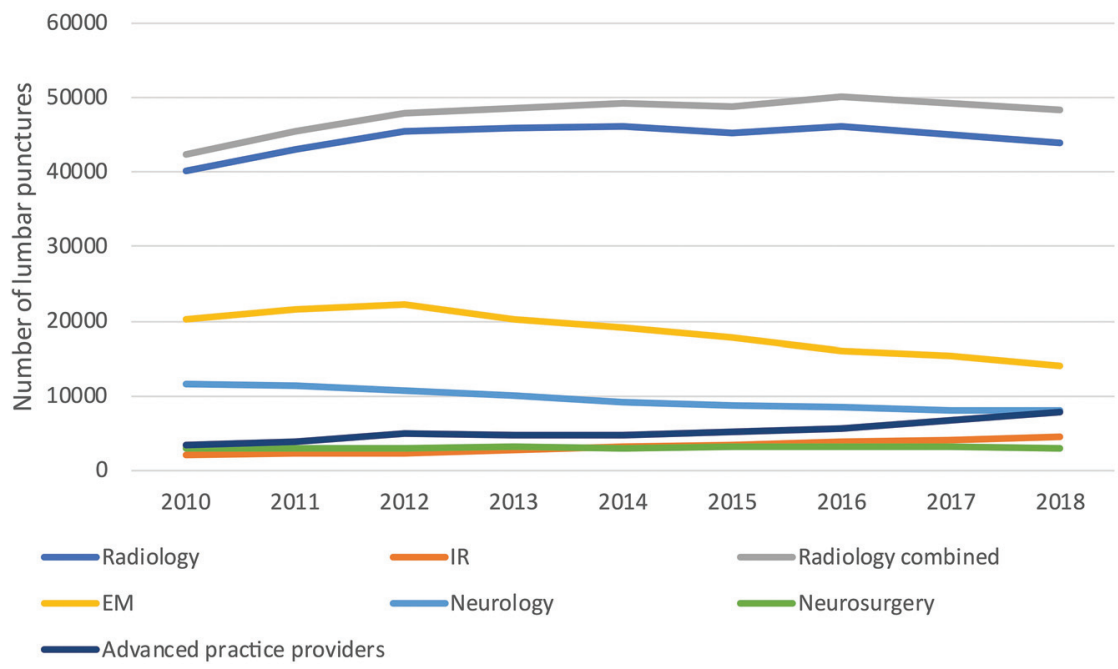

FIG 2. Overall lumbar puncture procedure shares in the United States from 2010 to 2018, by provider specialty. IR indicates interventional radiology; EM, emergency medicine.

1991 and 2011. ${ }^{1}$ The purpose of this study was to determine whether radiologists have continued to be the dominant provider of LP procedures stratified by place of service.

\section{MATERIALS AND METHODS}

Data were obtained from the Centers for Medicare \& Medicaid Services Physician/Supplier Procedure Summary Master Files from 2010 to 2018. These files contain summary tables for all beneficiaries of the nationwide Medicare Part B Fee-for-Service Compliance program (38.7 million in 2018). Data are available for each code in the Current Procedural Terminology, Fourth Edition (CTP-4) and include information such as procedure volume, provider specialty, location of services, and payments approved. Provider specialties were determined from the Physician Specialty Classification Codes used by Medicare. Locations at which examinations were performed were determined using Medicare Place-of-Service Codes.
For this study, we determined the number of lumbar punctures performed in hospital outpatient, inpatient, emergency department (ED), and office settings by analyzing the CPT- 4 codes contained in the billing claims filed by physicians. We reviewed all CPT-4 codes that represented lumbar punctures (62270 and 62272). For each category, we determined the total number of procedure claims from 2010 to 2018 . We also calculated the utilization rate per 1000 Medicare Fee-for-Service beneficiaries for each year. Data analysis was performed using Excel 2015 (Microsoft). These aggregated public use files contain no patient or physician identifiers and are, therefore, exempt from review by an institutional review board.

\section{RESULTS}

The overall number of LP procedures essentially has not changed between 2010 and 2018 (92,579 in 2010 and 92,533 in 2018). A minimal decrease in diagnostic LPs (86,347 versus 85,665$)$ and a slight increase in therapeutic LPs (6232 versus 6868) were noted.

For diagnostic LPs, the procedure rate per 1000 Medicare Fee-for-Service enrollees increased from 2.45 in 2010 to a peak of 2.56 in 2012, then gradually declined to 2.21 in 2018 ( $-13 \%$ versus peak). For therapeutic LPs, the procedure rate per 1000 Medicare Fee-forService enrollees varied minimally during the decade, from 0.177 in 2010 to a peak of 0.187 in 2016, before it gradually declined back to 0.177 in 2018 . For diagnostic and therapeutic LPs combined, the procedure rate per 1000 Medicare Fee-for-Service enrollees increased from 2.63 in 2010 to a peak of 2.73 in 2012, before it steadily declined to 2.39 in 2018 . This change corresponds to a $9 \%$ decrease in the overall procedure rate during the past decade (Fig 1).

Figure 2 shows the LP share by provider specialty. Overall, radiologists performed 42,296 LP procedures in 2010 versus 48,414 in 2018 , representing a $45.7 \%$ versus $52.3 \%$ procedure share, respectively. These numbers combine diagnostic and interventional radiologists. If evaluated separately, there is a striking increase in the number of cases performed by interventional radiologists: 2167 LPs in 2010 compared with 4459 LPs in 2018 $(+105.8 \%$ procedure volume). This represents an increase in the overall procedure share from $5.1 \%$ to $9.2 \%$ within the radiology subgroup and from $2.4 \%$ to $4.8 \%$ in the overall procedure share. Likewise, advanced practice providers (APPs) (mainly representing nurse practitioners and physician assistants) experienced an 
Distribution of diagnostic and therapeutic lumbar puncture procedures performed in 2010 and 2018, by specialty ${ }^{\mathrm{a}}$

\begin{tabular}{|c|c|c|c|c|c|c|c|c|}
\hline $\begin{array}{l}\text { Year, Type of } \\
\text { Procedure }\end{array}$ & Radiology & $\begin{array}{l}\text { Interventional } \\
\text { Radiology }\end{array}$ & Emergency & Neurology & Neurosurgery & Anesthesia & $\begin{array}{l}\text { Advanced } \\
\text { Practice } \\
\text { Providers }\end{array}$ & Others \\
\hline \multicolumn{9}{|l|}{2010} \\
\hline Total $(n=92,579)$ & 40,129 (43.3) & $2167(2.4)$ & $20,170(21.8)$ & $11,607(12.5)$ & $2960(3.2)$ & $3416(3.7)$ & $3388(3.7)$ & $8742(9.4)$ \\
\hline Diagnostic $(n=86,347)$ & $38,675(44.8)$ & $2060(2.4)$ & $20,124(23.3)$ & 10,814 (12.5) & $798(0.9)$ & $2415(2.8)$ & $3289(3.8)$ & $8172(9.5)$ \\
\hline Therapeutic $(n=6232)$ & $1454(23.3)$ & $107(1.7)$ & $46(0.7)$ & 793 (12.7) & $2162(34.7)$ & 1001 (16.1) & $99(1.6)$ & $570(9.2)$ \\
\hline \multicolumn{9}{|l|}{2018} \\
\hline Total $(n=92,533)$ & $43,955(47.5)$ & $4459(4.8)$ & $14,153(15.3)$ & $8126(8.8)$ & 2909 (3.2) & $2228(2.4)$ & $7785(8.4)$ & $8918(9.6)$ \\
\hline Diagnostic $(n=85,665)$ & $42,376(49.5)$ & $4187(4.9)$ & 14,063 (16.4) & $7426(8.7)$ & $603(0.7)$ & $1362(1.6)$ & $7380(8.6)$ & $8268(9.6)$ \\
\hline Therapeutic $(n=6868)$ & $1579(23.0)$ & $272(3.9)$ & $90(1.3)$ & $700(10.2)$ & $2306(33.6)$ & $866(12.6)$ & $405(5.9)$ & $650(9.5)$ \\
\hline
\end{tabular}

${ }^{\mathrm{a}}$ Data are number (\%) of procedures.

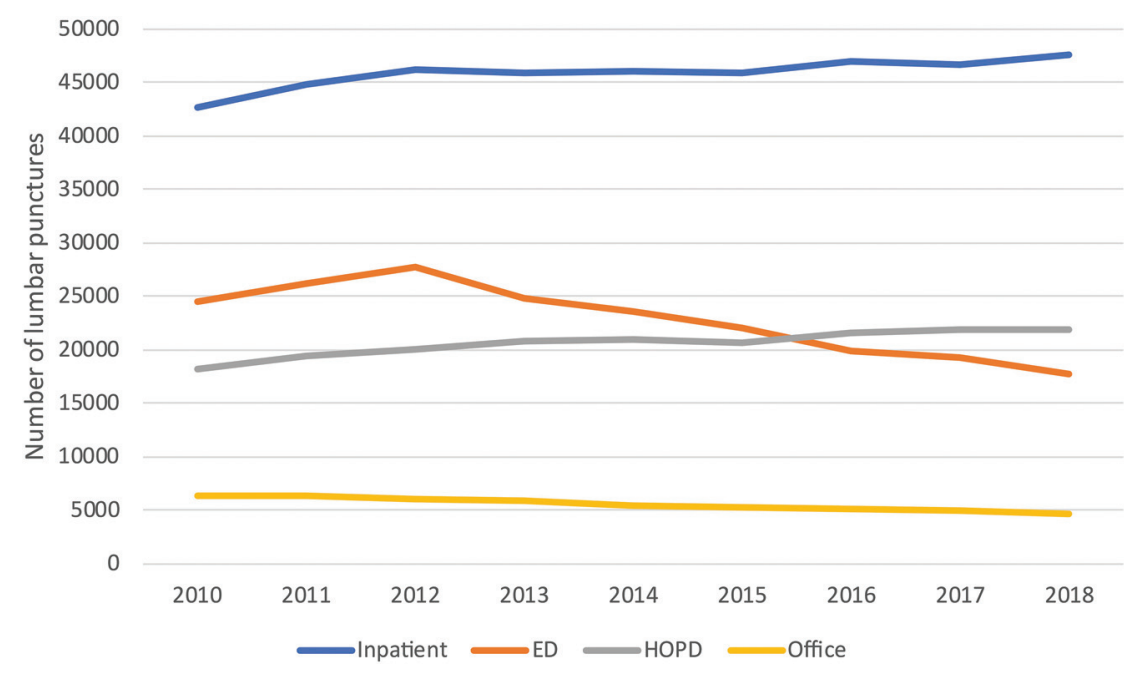

FIG 3. Lumbar puncture procedures in the United States from 2010 to 2018, by place of service performed. HOPD indicates hospital outpatient department.

17,701 in $2018 ;-27.8 \%$ procedure volume). Last, in hospital outpatient departments, the procedure volume has progressively increased (18,200 in 2010 versus 21,889 in 2018), while the private office volume has steadily decreased (6287 in 2010 versus 4672 in 2018).

Figure 4 illustrates the overall procedure share changes by specialty. From 2010 to 2018, the market share for radiologists/interventional radiologists and APPs has increased for diagnostic LPs, while it has declined the most for emergency medicine physicians and neurologists. For therapeutic LPs, neurosurgery keeps the largest market share $(33.6 \%$ in 2018 , a $-1.1 \%$ decrease), followed by radiology $(26.9 \%$ in 2018 , a $+1.9 \%$ increase); however, within the radiology subgroup, interventional radiologists have increased

increase in the overall procedure share from 3.7\% in 2010 to $8.4 \%$ in 2018 (3388 LPs in 2010 versus 7785 LPs in 2018; + 129.8\% procedure volume). Besides radiologists, the 2 other major physician groups performing LPs include emergency medicine physicians and neurologists. Emergency medicine physicians and neurologists had a decrease in total numbers and procedure share during the past decade $(21.8 \%$ versus $15.3 \%$, and $12.5 \%$ versus $8.8 \%$, respectively). Besides, a substantial number of total LPs were performed by various known and unknown providers, summarized as "others." Known specialties in this category include internal, pulmonary, and critical care medicine, which performed 4701 LPs in 2018 combined, correlating with a 5.1\% procedure share.

Neurosurgery continued to be the leading provider for therapeutic LPs throughout the decade (2306 LPs in 2018, procedure share of $33.6 \%$ ), followed by radiologists (1851 LPs in 2018, procedure share of $26.9 \%$ ). The Table demonstrates the distribution of diagnostic and therapeutic LP procedures performed by specialty for 2010 and 2018 .

By far, most of the LP procedures were performed in the inpatient hospital setting (42,685 in 2010 versus 47,533 in 2018), with a $5.3 \%$ increase in procedure share during the decade (Fig 3). The LP procedure volume in the ED has drastically decreased, recording a $7.4 \%$ decrease in the overall procedure share $(24,519$ in 2010 versus their procedure share for therapeutic LPs (3.9\% in 2018, a $2.2 \%$ increase), while for noninterventional radiologists, the procedure share remained relatively stable (23.0\% in 2018 , a $0.3 \%$ decrease).

\section{DISCUSSION}

Kroll et $\mathrm{al}^{1}$ demonstrated that between 1991 and 2011, LP procedures on Medicare beneficiaries have increased, with radiology becoming the dominant overall provider. While this previous study depicted a roughly 4 -fold increase of the LP procedure share for radiologists during 2 decades, the present study shows smaller differences but a continuation of this trend and changes in procedure shares among physician and nonphysician groups.

Although being already the dominant overall provider at the beginning of the previous decade, interventional and noninterventional radiologists combined had the largest procedure share increase during the past 9 years of all groups. This contrasts with many other areas of image-guided procedures in which "turf wars" continue to emerge among different specialties, often to the disadvantage of radiologists. ${ }^{8}$ Various minimally invasive procedures, originally developed and performed by radiologists, such as coronary angiography, neurointerventional procedures, or noncardiac peripheral vascular interventions, are now mainly performed by other specialists, including cardiologists, neurosurgeons, and vascular surgeons. ${ }^{9-11}$ 


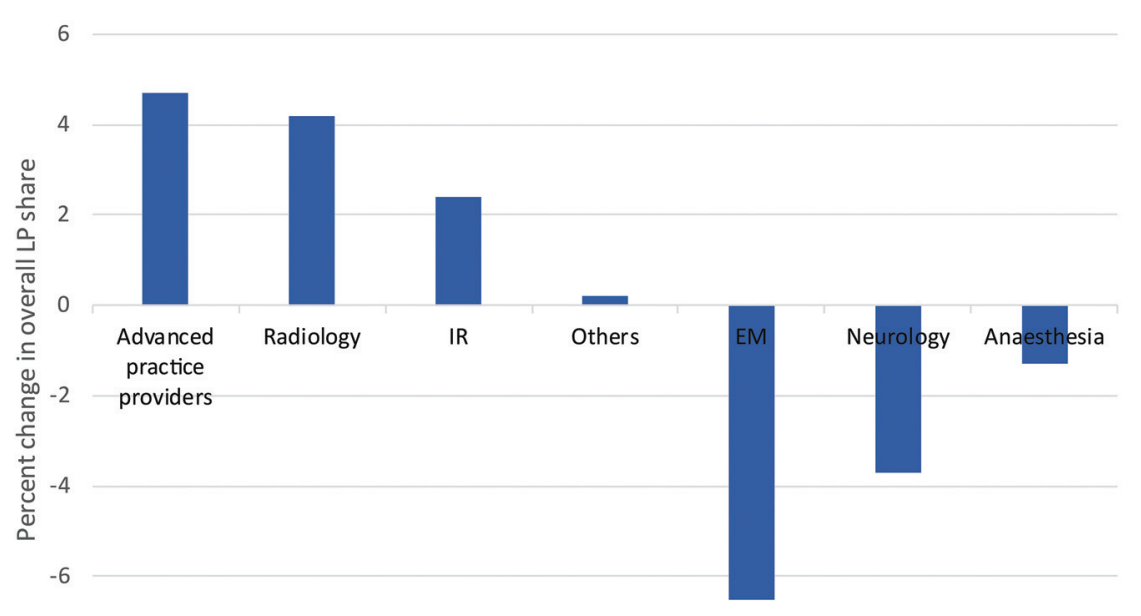

$-8$

FIG 4. Overall lumbar puncture procedure share changes from 2010 to 2018 by provider specialty. IR indicates interventional radiology; EM, emergency medicine.

Even though there is a provider specialty shift toward radiologists, the underlying reasons leading to this development are likely not solely attributable to the advantages of image guidance or the growing of radiologists' expertise. LPs are time-consuming procedures with relatively low reimbursement rates. In 2018, the national average Medicare physician payment for a diagnostic LP performed was $\$ 64.30$, and for a therapeutic LP, it was $\$ 69.55$. In contrast, the Medicare payment for reporting a brain MR imaging with and without contrast was $\$ 128.60$, and for a lumbar spine MR imaging without contrast, it was $\$ 96.58$. Additionally, to be able to perform image-guided LPs, other resources such as a fluoroscopy/ CT system and a radiology technologist are required. A similar development has been shown with paracentesis and thoracentesis procedures, for which radiologists became the main provider during the past decades, ${ }^{12}$ in part due to unfavorable economics that are comparable with that of LP procedures. Simultaneously, the demand for productivity and workload has increased for radiologists and clinicians alike, ${ }^{13-16}$ contributing to the relatively low-paid/ time-consuming procedures, which could further aggravate stress in daily clinical practice, being, instead, referred to other services.

Nevertheless, this trend also offers distinct opportunities for radiologists. While there is no doubt that radiology services are indispensable to the care of patients, concerns about a prestige problem have been raised in the past by various leaders in the field, ${ }^{17}$ and there is broad agreement that it is crucial for the future of radiology to have more direct patient contact. This concept can contain different aspects of patient-centered care and, depending on the subspecialty, may include minimally invasive procedures, outpatient care, or better communication with the patient. ${ }^{18,19}$ Furthermore, by reinforcing their role in patient care, radiologists can improve their reputation and strengthen relationships with referring providers. ${ }^{20}$

Another emerging trend demonstrated in this study is the marked increase in procedure shares among APPs. APPs recorded the largest rise in procedure shares among all groups when radiologists and interventional radiologists are considered separately.
Likewise, the overall procedure shares of APPs in 2018 are only minimally lower compared with those of neurologists, a previously dominant specialty for LPs. This practice is concurrent with developments described for other procedures such as paracentesis, thoracentesis, fine-needle aspirations and biopsies, and reported nationwide performances of nonvascular invasive procedures by APPs of between approximately $1 \%$ and $11 \% .{ }^{21}$ Reasons for this change are multifactorial, with the progressing physician shortage certainly playing a major role. ${ }^{22}$ This trend is likely going to continue, especially with the growing acceptance and comparable procedure outcomes between trained APPs and physicians. ${ }^{21,23,24}$

After a peak in 2012, there has been a steady decline in the performance of LP procedures in EDs. During the previous decades, overcrowding in EDs has become a well-known reality, ${ }^{25,26}$ and an increasing number of ED visits has likely further aggravated this situation. ${ }^{27}$ Therefore, the development observed in our study might be a reflection of increased demand for throughput in EDs. This change represents a reversal of earlier decade trends, which showed a marked increase of LP procedures in EDs. ${ }^{1}$ A decrease in the length of a hospital stay for many diseases/conditions may contribute to an accelerated transfer from the ED to the inpatient setting and the observed increase of inpatient LPs. Outpatient LPs are predominantly performed in the hospital outpatient department setting, which demonstrated steady growth, a development that led to more LPs being performed in the hospital outpatient department setting from 2016 onward than in the ED. Finally, a decreasing number of LPs were performed in private offices during the past decade; however, this represents a continuation of earlier decade trends. ${ }^{1}$

Limitations of this study include, besides its retrospective nature, that Physician/Supplier Procedure Summary Master Files only pertain to the Medicare Part B Fee-for-Service population and our study results are not generalizable because patients with coverage from other federal programs, private health insurance, or those uninsured are not included. Nevertheless, the Physician/ Supplier Procedure Summary Master Files are frequently used for this type of study because they are the largest and most reliable data source. Also, due to the increasing share of LPs performed by APPs, the overall percentages for major specialties could be affected if a different number of APPs work under the aegis of supervising specialty groups. However, although LPs performed by APPs are increasing, it is questionable whether they cause significant differences among specialties yet, and they should not account for the observed trends in this study. Further investigations are needed to determine a potential relation between LP procedure shares and the number of APPs working under different specialties. 


\section{CONCLUSIONS}

The LP procedure volume remained stable during the past decade, with a shift in procedure volume from the ED and private offices to the hospital setting. Radiologists continue to be the dominant provider with a further increase in procedure shares for both noninterventional and interventional radiologists. Besides radiologists, APPs experienced a large increase in procedure volume, which reflects nationwide trends for other nonvascular invasive procedures performed by APPs.

\section{REFERENCES}

1. Kroll H, Duszak R Jr, Nsiah E, et al. Trends in lumbar puncture over 2 decades: A dramatic shift to radiology. AJR Am J Roentgenol 2015;204:15-19 CrossRef Medline

2. Brook AD, Burns J, Dauer E, et al. Comparison of CT and fluoroscopic guidance for lumbar puncture in an obese population with prior failed unguided attempt. J Neurointerv Surg 2014;6:324-28 CrossRef Medline

3. Soni NJ, Franco-Sadud R, Schnobrich D, et al. Ultrasound guidance for lumbar puncture. Neurol Clin Pract 2016;6:358-68 CrossRef Medline

4. Costerus JM, Brouwer MC, van de Beek D. Technological advances and changing indications for lumbar puncture in neurological disorders. Lancet Neurol 2018;17:268-78 CrossRef Medline

5. Eskey CJ, Ogilvy CS. Fluoroscopy-guided lumbar puncture: decreased frequency of traumatic tap and implications for the assessment of CT-negative acute subarachnoid hemorrhage. AJNR Am J Neuroradiol 2001;22:571-76 Medline

6. Hales CM, Fryar CD, Carroll MD, et al. Trends in obesity and severe obesity prevalence in US youth and adults by sex and age, 20072008 to 2015-2016. JAMA 2018;319:1723-25 CrossRef Medline

7. Hudgins PA, Fountain AJ, Chapman PR, et al. Difficult lumbar puncture: pitfalls and tips from the trenches. AJNR Am J Neuroradiol 2017;38:1276-83 CrossRef Medline

8. Bello J. Turf issues in radiology and its subspecialties. Neuroimaging Clin N Am 2012;22:411-19 CrossRef Medline

9. Baum RA, Baum S. Interventional radiology: a half century of innovation. Radiology 2014;273:S75-91 CrossRef Medline

10. Veith FJ. A look at the future of vascular surgery. J Vasc Surg 2016;64:885-90 CrossRef Medline

11. Choke E, Sayers R. Viewpoint: adaptation of vascular surgery in the interventional era. Heart 2015;101:342-45 CrossRef Medline
12. Duszak R Jr, Chatterjee AR, Schneider DA. National fluid shifts: fifteen-year trends in paracentesis and thoracentesis procedures. $J$ Am Coll Radiol 2010;7:859-64 CrossRef Medline

13. Chetlen AL, Chan TL, Ballard DH, et al. Addressing burnout in radiologists. Acad Radiol 2019;26:526-33 CrossRef Medline

14. Fiscella K, Epstein RM. So much to do, so little time: care for the socially disadvantaged and the 15-minute visit. Arch Intern Med 2008;168:1843-52 CrossRef Medline

15. Watson AG, McCoy JV, Mathew J, et al. Impact of physician workload on burnout in the emergency department. Psychol Health Med 2019;24:414-28 CrossRef Medline

16. Nassar AK, Waheed A, Tuma F. Academic clinicians' workload challenges and burnout analysis. Cureus 2019;11:e6108 CrossRef Medline

17. Levin DC, Rao VM. Radiology's image problem: ponder the words of some thought leaders in the field. J Am Coll Radiol 2008;5:616-18 CrossRef Medline

18. European Society of Radiology 2009. The future role of radiology in healthcare. Insights Imaging 2010;1:2-11 CrossRef Medline

19. Siskin G. Outpatient care of the interventional radiology patient. Semin Intervent Radiol 2006;23:337-45 CrossRef Medline

20. Boland GW. Visibility of radiologists: Helping to secure your future. AJR Am J Roentgenol 2009;192:1373-74 CrossRef Medline

21. Duszak R Jr, Walls DG, Wang JM, et al. Expanding roles of nurse practitioners and physician assistants as providers of nonvascular invasive radiology procedures. J Am Coll Radiol 2015;12:284-89 CrossRef Medline

22. Kirch DG, Petelle K. Addressing the physician shortage: the peril of ignoring demography. JAMA 2017;317:1947-48 CrossRef Medline

23. Murphy FB, Walls G, Tridandapani S, et al. Comparison of imageguided nonfocal hepatic biopsies performed by physicians and nurse midlevel providers. J Am Coll Radiol 2014;11:1059-63 CrossRef Medline

24. Gilani N, Patel N, Gerkin RD, et al. The safety and feasibility of large volume paracentesis performed by an experienced nurse practitioner. Ann Hepatol 2009;8:359-63 CrossRef Medline

25. Dickinson G. Emergency department overcrowding. CMAJ 1989;140:270-71 Medline

26. Trzeciak S, Rivers EP. Emergency department overcrowding in the United States: an emerging threat to patient safety and public health. Emerg Med J 2003;20:402-05 CrossRef Medline

27. Lane BH, Mallow PJ, Hooker MB, et al. Trends in United States emergency department visits and associated charges from 2010 to 2016. Am J Emerg Med 2020;38:1576-81 CrossRef Medline 